\title{
Features of fretting fatigue strength/life and its mechanical considerations
}

\author{
T. Hattori, M. Yamashita \& N. Nishimura \\ Department of Mechanical and System Engineering, Gifu University, \\ Gifu, Japan
}

\begin{abstract}
The fretting fatigue process has many features such as early stage crack initiation at the contact edge, very slow crack propagation and fatigue failure after a very long life operation. In a previous paper we presented a new fretting fatigue model which can explain these fretting fatigue features reasonably. In this paper we try to explain many other fretting features such as fretting fatigue strength and life dependence on contact pressure and contact edge shapes. Firstly we try to discuss the dependence of fretting fatigue strength/life on contact pressure. In accordance with the increase of the contact pressure the stress concentration at the contact edge increased and crack initiation stress level decreased. But to open these small cracks initiated at contact edges more wear or more load cycles are needed. So fretting fatigue strength limit decreased in accordance with the increase of contact pressure and fretting fatigue life increased in accordance with the increase of contact pressure. Then we discuss the fretting fatigue strength dependence on the contact edge shape, such as stress release projection or interference of the contact edge with the stress concentration fillet. Experimental results of fretting fatigue strength improvement with stress release projection can be explained analytically. The two-stage S-N curve can be shown in joint structures, in which contact edge is set near the stress concentration fillet. These features can also be explained analytically in this paper.

Keywords: fretting fatigue, fretting wear, contact pressure, contact edge shape, stress singularity parameter, stress intensity factors.
\end{abstract}




\section{Feature of fretting fatigue}

The fretting fatigue process has many features such as early stage crack initiation at contact edge, very slow crack propagation and fatigue failure after very long life operation. For instance 660MW turbogenerator rotor failed in England during the 1970s as a result of fretting fatigue cracking as shown in Fig. 1[3]. In this case the loading cycles in just one year is about $1.6 \times 10^{9}$ and this trouble was observed after many years operation. Firstly the biggest question for turbogenerator design engineers is that, why the fatigue crack propagates so wide an area in the rotor cross section after very long life operation. The answer is that, the operating stress amplitude is very low less than $10 \mathrm{MPa}$ and crack propagate very slowly. Then the next question is that why the crack initiate under these low stress amplitude. In that time there was no enough answer except fretting under residual stress and crack initiation under barring conditions.

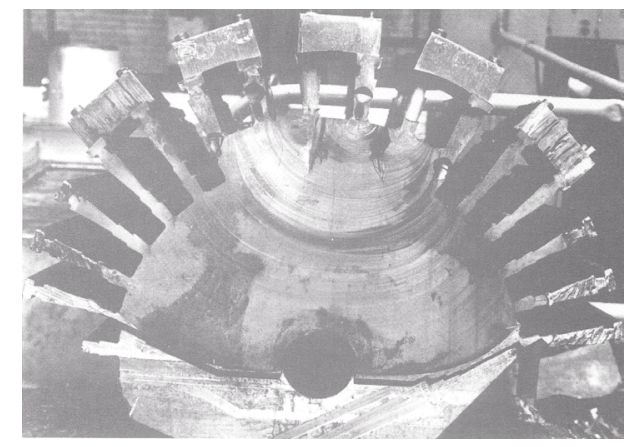

Figure 1: Fretting fatigue failure example of turbogenerator rotor. After Lindley and Nix [3].

\section{Fretting fatigue mechanisms}

I think that above mentioned ultra high cycle fatigue life can't be explained using only initial stress analysis results. We can't neglect the wear of the contact surfaces near contact edge and change of contact pressure in accordance with the progress of wear. Here, in this paper we present fretting fatigue process model as illustrated in Fig. 2. Cracking due to fretting fatigue starts very early in fretting fatigue life. We used stress singularity parameters at the contact edge to estimate the initiation of these cracks [4-6]. During this early period, fretting fatigue cracks tend to close and propagate very slow, due to the high contact pressure acting near this contact edge. But wear on the contact surface reduces the contact pressure near the contact edge, and cracks gradually start to propagate. Hence, fretting fatigue life will be dominated by the propagation of this small cracks initiated at the contact edge. So to estimate the fretting fatigue strength or life, the precise estimation of the fretting wear progress is indispensable. The propagation life in long crack length region can be estimate using ordinal 
fracture mechanics. In this paper we discuss the estimation method of wear extension on contact surfaces near the contact edge, and present the fretting fatigue crack propagation estimation method considering fretting wear extension.

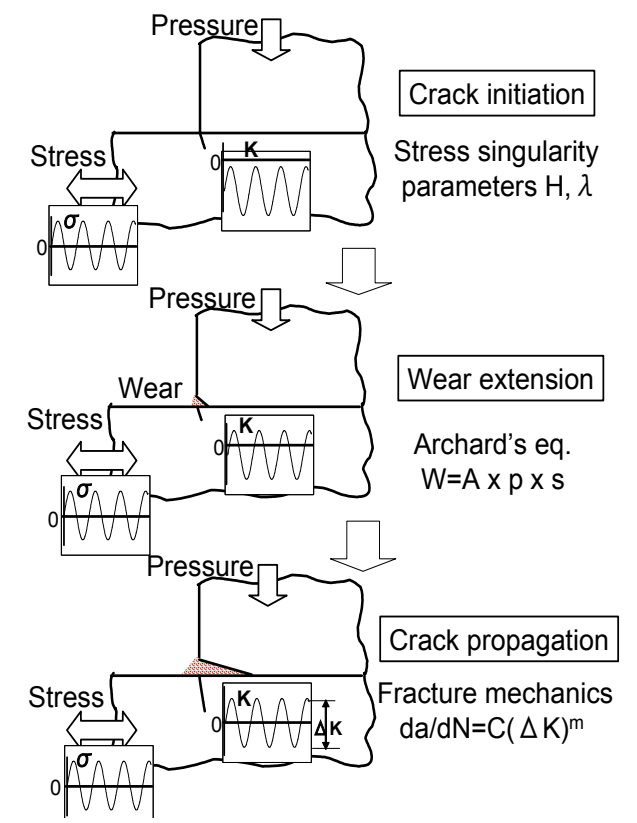

Figure 2: Fretting fatigue mechanisms in various processes.

Then I will show the flow of fretting fatigue life analysis considering the extension of fretting wear In Fig. 3. Firstly the fretting wear amount is estimated using contact pressure and relative slippage on each loading condition. Then the shapes of contact surfaces are modified following the fretting wear amount. And finally fretting crack extension or arrest evaluation is performed using fracture mechanics, if the operating $\Delta \mathrm{K}$ is higher than the threshold stress intensity factor range $\Delta \mathrm{K}_{\mathrm{th}}$.

We can estimate this load cycle as fretting life, and if the operating $\Delta \mathrm{K}$ is lower than the threshold stress intensity factor range $\Delta \mathrm{K}_{\text {th }}$ fretting wear amount is estimated using new contact pressure and new relative slippage and repeat these process until operating $\Delta \mathrm{K}$ reach to the threshold stress intensity factor range $\Delta \mathrm{K}_{\text {th }}$.

And using this flow chart I estimated as shown in Fig. 3 by solid line. This estimated S-N curves especially in ultra high cycle region is compared with the experimental results and both results coincide well and this tendency of decrease of fretting fatigue strength especially in ultra high cycle region can explain above mentioned fretting troubles in industrial fields. 


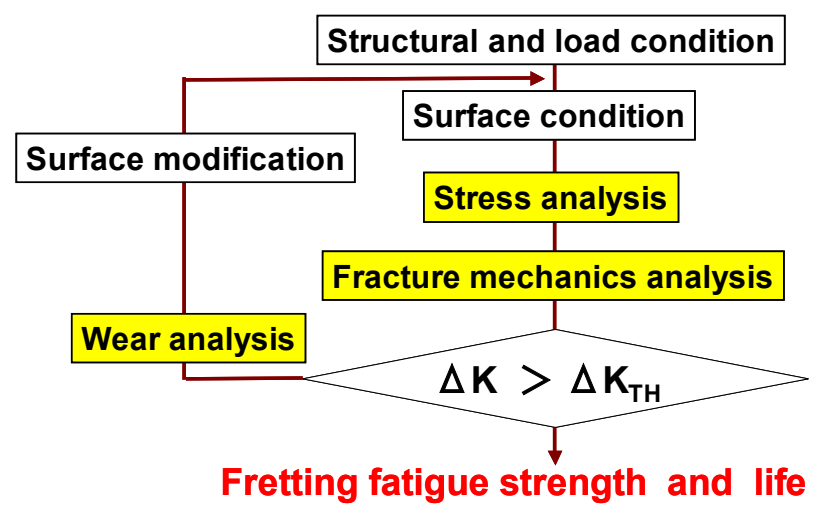

Figure 3: $\quad$ Flow chart of fretting fatigue life analysis.

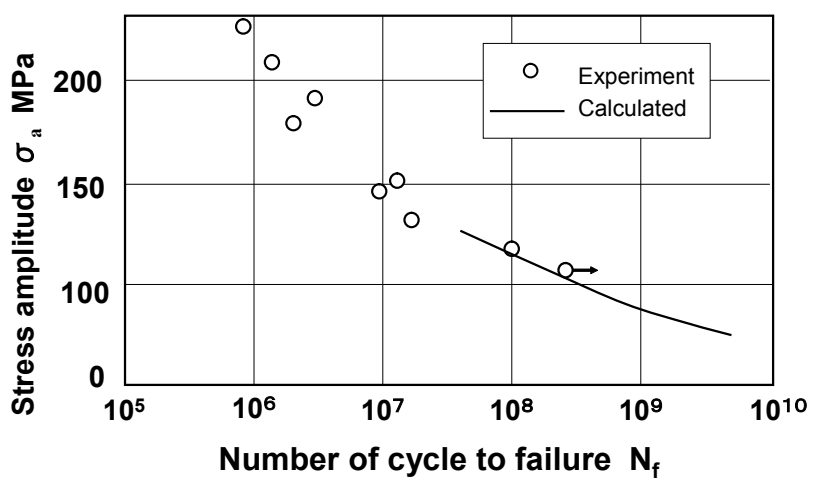

Figure 4: $\quad$ Estimated and experimental fretting fatigue S-N curves.

From these estimated results considering fretting fatigue processes such as crack initiation, wear extension and crack propagation, we can propose the general view of fretting fatigue S-N curve as shown in Fig. 5. The S-N curve in high stress region can be obtained without consideration of fretting wear. But in low stress and high cycle region we must consider the fretting wear extension. To estimate the S-N curve especially in ultra high cycle region more than $10^{8}$, $10^{9}$ we can use the hint that this S-N curve will converge to the crack initiation limit as an asymtote as sown in Fig. 5.

\section{Mechanical consideration for some fretting fatigue features}

\subsection{Fretting fatigue strength / life dependence on contact pressure}

In Fig. 6 we show the estimated example of dependence of fretting fatigue strength / life on contact pressure. In accordance with the increase of the contact 
pressure the stress concentration at contact edge increase and crack initiation stress level decreased. But to open this small cracks initiated at contact edges more wear or more load cycles are needed. So fretting fatigue strength limit decrease in accordance with the increase of contact pressure and fretting fatigue life increase in accordance with the increase of contact pressure. This estimated results coincided well with the experimental results as shown in Fig. 7 [7].

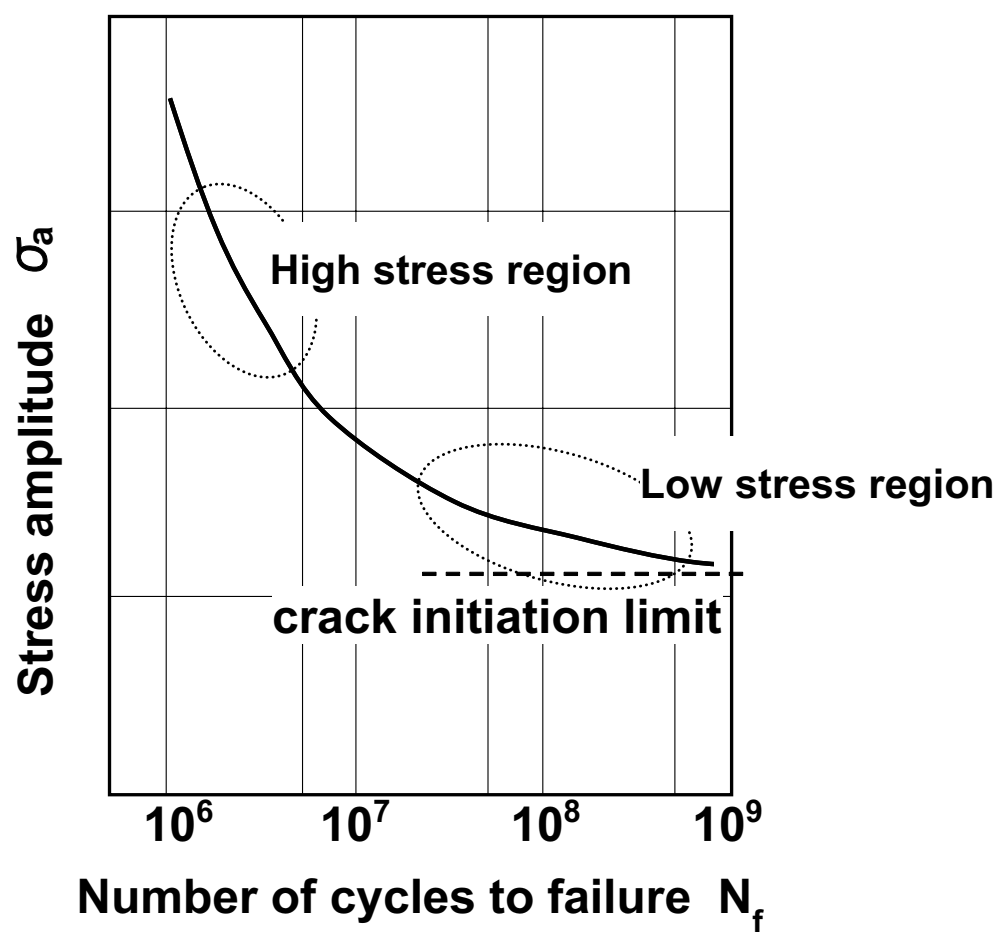

Figure 5: Schematic view of fretting fatigue S-N curve.

\subsection{Fretting fatigue strength / life dependence on contact edge shape}

To improve the fretting fatigue strength, the stress release projection is sometimes made on contact edge as shown in Fig. 8 [8]. This projection piece reduces the local stiffness and releases the pressure and stress concentration near contact edge. This reduction of stress concentration at contact edge improves the crack initiation limit, and similarly reduction of contact pressure concentration at contact edge decrease the wear rate and so increase the fretting fatigue life. This tendency can be seen in Fig. 8. By making a suitable projection near contact edge, the fretting fatigue strength can be improved about $30 \%$ compared with that of plain fretting model. 


\subsection{Fretting fatigue strength / life estimation considering the interference with stress concentration fillet}

In many joint structures we must set contact edge near a fillet as shown in Fig. 9 [8]. In these cases we must consider the interference of stress concentration at contact edge with that at fillet. In the case of Fig. 9 both the stress and pressure concentration at contact edge decrease and fretting fatigue strength / life increase as the crack initiation limit increase and wear rate decrease. But, the most important notice in structural design of these joint is that if we mistake the fillet shape the fatigue at fillet decrease and it regulate the fatigue strength of joint structure. Fig. 9 shows the shrink fitted shaft coupling with fillet. In this case the fretting fatigue strength increase in accordance with the increase of stress concentration at fillet (decrease of fillet radius $\rho$ ). From this result we can see that the best choice of fillet radius is near $7 \mathrm{~mm}$ or more small $6 \mathrm{~mm}$. On this condition the fretting fatigue strength at contact edge become same with fatigue strength at fillet. And S-N curve just on near this condition show two-stage curve as shown in Fig. 9. The reason of this feature is the slow propagation behavior of fretting cracks accompanying with the wear extension.

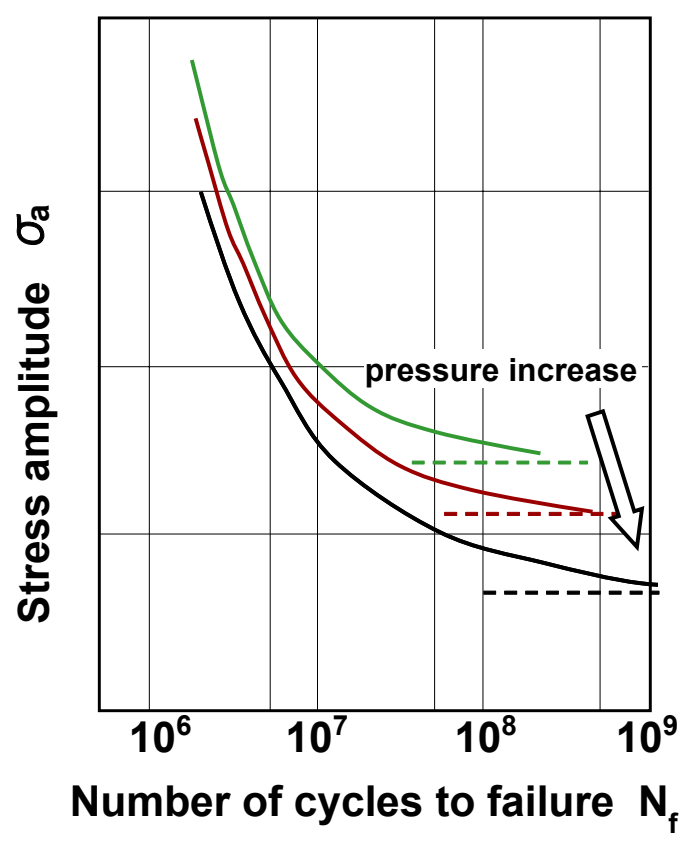

Figure 6: Estimated fretting fatigue strength dependence on contact pressure.

The next example of interference of contact edge with fillet is shown in Fig. 10. Unfortunately in this case the interference of contact edge with fillet increases both stress and contact pressure concentration at contact edge and 
decreases the fretting fatigue strength. In Japan many trouble happened on the hub structure of trailer truck as shown in this figure. Ordinary we test the fretting fatigue strength of whole parts before delivering these products to confirm the reliability. In these fatigue tests the most important notice is that fretting fatigue strength / life can't be confirmed in the ordinal load cycle number range such as $10^{7}$ In these load cycle number range we ca only confirm the fatigue strength at fillet. As mentioned above the fretting fatigue failure at contact edge appears after long life with wear extension. So to confirm the reliability of these joint structures we must perform the fatigue test more than $10^{8}$ or $10^{9}$ cycles.

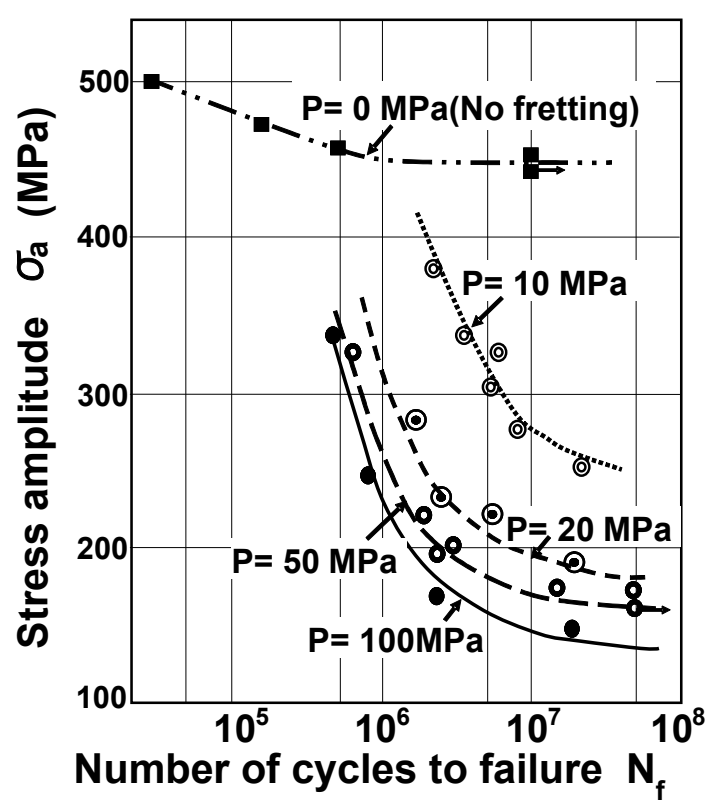

Figure 7: Experimental results of fretting fatigue strength for each contact pressure [7].

\section{Conclusions}

Fretting fatigue strength / life of several contact conditions are estimated based on the fretting fatigue model, which we presented before, as follows.

1. Fretting fatigue strength and life dependence on contact pressure was estimated and these results coincide well with the experimental results.

2. The interference of contact edge with ordinal fillet structure is analyzed and the existence of two stage S-N curve can be estimated. By using these results we present the methodology for designing optimum fillet shape and for confirming the reliability by fatigue test. 


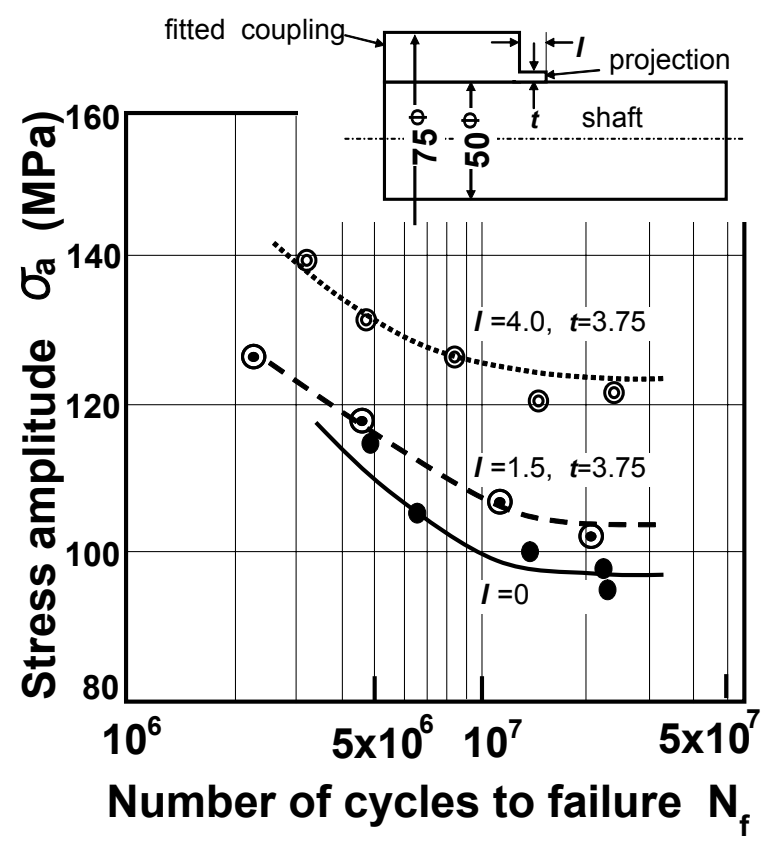

Figure 8: Experimental results of fretting fatigue strength improvement by making the projection at contact edge [8].

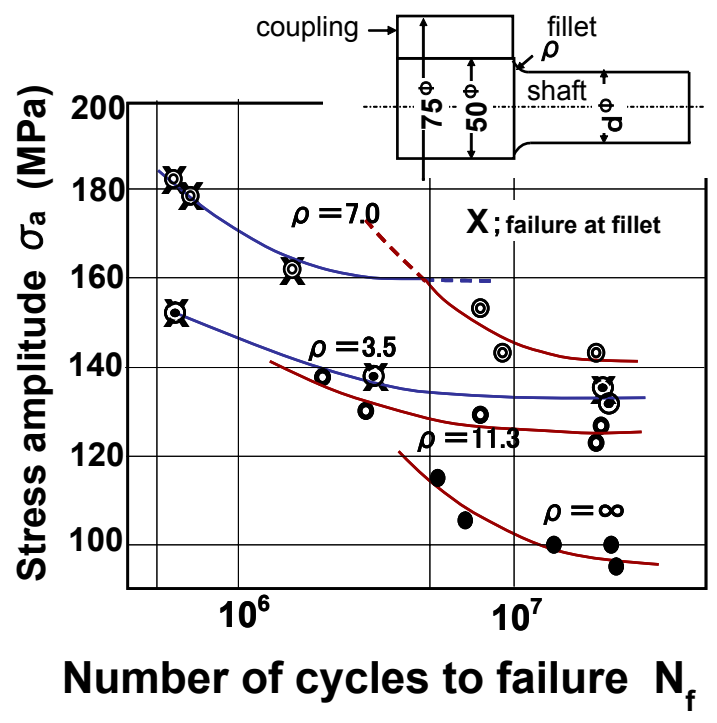

Figure 9: Experimental results of fretting fatigue strength of shrink fitted shaft coupling with fillet [8]. 

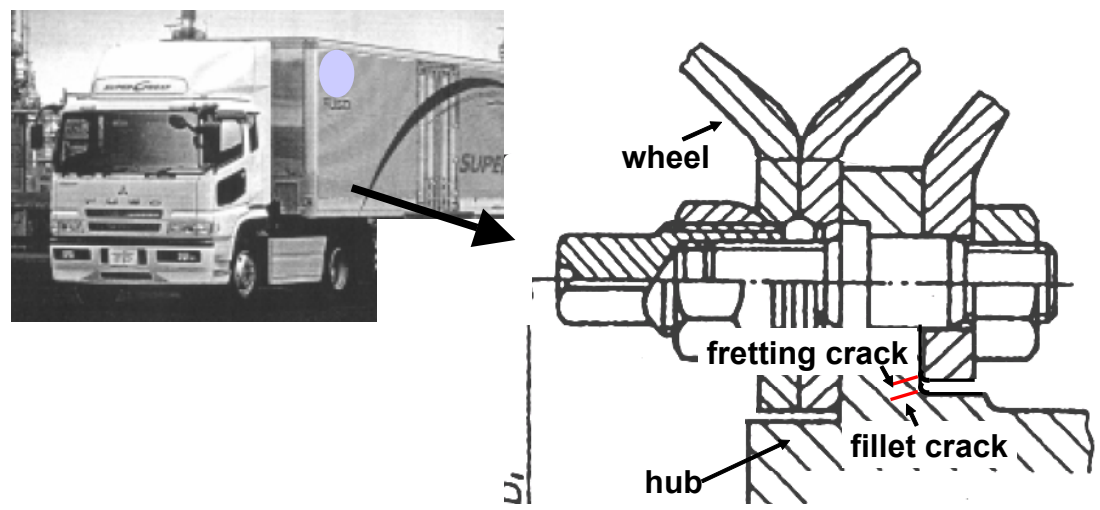

Figure 10: Hub-wheel joint structure in trailer.

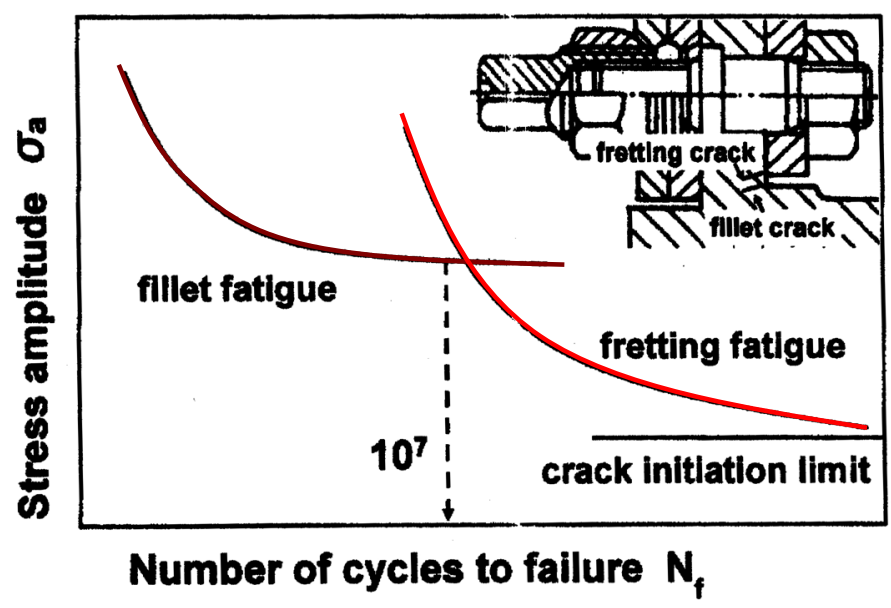

Figure 11: Two stage S-N curve of joint structure with contact edge and fillet.

\section{References}

[1] Hattori, Tand Watanabe, T., Fretting wear and fretting fatigue process at the contact edge, Computational Methods in Contact Mechanics VI, WIT Press, 2003, p.169-178.

[2] Hattori, T. and Watanabe, T., Fretting fatigue strength estimation considering the fretting wear process, Tribology International, 2006, 39, p.1100-1105.

[3] Suresh, S., Fatigue of Materials 2nd Edition, Cambridge University Press, 1998, p. 469.

[4] Hattori, T., Sakata, H. and Watanabe, T., A stress singularity parameter approach for evaluating adhesive and fretting strength, ASME Book No. G00485, MD-vol.6, 1988, p. 43. 
[5] Hattori, T. and Nakamura, N., Fretting fatigue evaluation using stress singularity parameters at contact edges, Fretting Fatigue, ESIS Publication 18, 1994, p. 453.

[6] Hattori, T., Nakamura, M. and Watanabe, T., Simulation of fretting fatigue life by using stress singularity parameters and fracture mechanics, Tribology International, 2003, 36, p. 87.

[7] Funk, W., Materialpruf, 1969, 11, 7, p.221.

[8] Nishioka, K. and Komatsu, H., Trans. Of JSME (in Japanese), 1967, 33, 248, p.503-511. 